\title{
Optimal Public Goods Provision: Implications of Endogenizing the Labor/Leisure Choice
}

\author{
Nicholas E. Flores and Philip E. Graves
}

\begin{abstract}
Conventional analysis of public goods provision aggregates individual willingness to pay while treating income as exogenous, ignoring the fact that we generate income to allow us to purchase utility-generating goods. We explore the implications of endogenizing the laborlleisure decision by explicitly considering leisure demand in a model of public goods provision. We consider benefit analysis of public goods provision and find that increments of the public good will generally be under-valued using conventional analysis while decrements to the public good (rare in public good settings) will be overvalued. (JEL C91, D61, Q51)
\end{abstract}

\section{INTRODUCTION}

The public goods provision problem is undoubtedly one of the most celebrated economic problems. Samuelson (1954) presented us with an elegant characterization of a socially optimal provision of private and public goods. In his seminal paper Samuelson wrote "provided economic quantities can be divided into two groups, (1) outputs or goods which everyone wants to maximize; and (2) inputs or factors which everyone wants to minimize, we are free to change the algebraic signs of the latter category and from then on work only with 'goods,' knowing that the case of factor inputs is covered as well." According to Samuelson's analysis, time available for leisure and labor is simply another scarce commodity. Like Robinson Crusoe's corn, time can be eaten, that is, consumed, or put to productive use.

While Samuelson's analysis is sufficiently general to handle the optimal allocation of time in the context of public and private goods, subsequent attempts to implement

Land Economics • November 2008 • 84 (4): 701-707 ISSN 0023-7639; E-ISSN 1543-8325

(C) 2008 by the Board of Regents of the

University of Wisconsin System
Samuelson's ideal through economic welfare analysis fail to consider the joint consumptive and productive aspects of time. Income earned comes at an opportunity cost of less time spent with family and/ or less time pursuing activities that detract from earned income. Welfare economics simply views a higher income as better than a lower income without regard to the additional sweat and toil needed to obtain this higher income. ${ }^{1}$ Separating the analysis of public goods (as well as changes in market prices) from the act of income generation has firm practical roots. The welfare analyst rarely, if ever, obtains data that is rich enough to model preferences for public goods, private goods, and personal time allocation. Cross-sectional data provides income variation without any regard to the relative sacrifice to obtain the income variation seen in those data. Given data limitations and the fact that welfare economics is essentially an applied science, it is no surprise that welfare economics treats income as a given. Thus while Samuelson's analysis may view time as just another commodity, the practice of welfare economics, where the rubber meets the road in the analysis of public goods, fails even to treat time as a scare economic quantity.

The authors are, respectively, associate professor and professor, Department of Economics, University of Colorado. The authors would like to specifically thank Amit Batabyal, Charles deBartolome, Don Fullerton, John List, V. Kerry Smith, Laura Taylor, George Tolley, Randy Walsh, and Stephan Weiler for input on earlier variants of this paper. We are additionally grateful for numerous seminar/workshop comments at the University of Chicago, University of Colorado, Colorado State University, George Mason University, Georgia State University, University of Missouri, North Carolina State University, Rochester Institute of Technology, and the University of Wyoming. The authors accept responsibility for any errors.

'One notable exception is found in the appendix of Just, Hueth, and Schmidt (1982). 
As economists love to point out, there is no such thing as a free lunch, and this phrase applies to the welfare analysis of public goods. As we demonstrate below, failure to recognize the dual consumptive and productive aspects of time leads to a biased analysis of public goods. Because people work to buy the things they desire, the problem is not simply that of failing to identify the correct level of public goods. Failure to find the correct level of public goods implies failure to find the correct level of income as well. Thus, the output failure associated with free riding is accompanied by an input failure in the labor market. ${ }^{2}$ Though practical data limitations may always confound an ideal analysis of public goods, the implications of falling short of this ideal are nonetheless important.

\section{BENEFIT ANALYSIS AND INPUT MARKET DECISIONS}

Standard welfare analysis for valuing a change in a quantity-rationed public good typically treats income as being given at initial fixed levels. This implicitly assumes that leisure demanded/labor supplied, is constrained to the status quo level and that the status quo level of income is the optimal level. The LeChatelier-Samuelson Principle implies that if we constrain a person to the same level of leisure, then the gain in utility for an increase in the public good will be less than if we allow for adjustment in leisure. ${ }^{3}$ The compensating surplus/willingness to pay for the increase under constrained leisure choices is shown here to be less than willingness to pay under a regime of free choice of leisure. Similarly for a reduction in the public good, willingness to accept compensation will also be greater than if we had allowed for leisure adjustment. This

\footnotetext{
${ }^{2}$ Free riding in input markets is discussed further in Graves (2004). Here we pursue the theoretical implications of failure to endogenize the labor/leisure decision.

${ }^{3}$ As discussed in Graves (2004), this problem is exacerbated when the initial level of leisure is itself nonoptimal due to what Graves refers to as the input market failure.
}

second case is seldom of relevance in practical policy settings where improvements in, for example, air or water quality are being considered.

Our general model is very similar to standard models of public goods provision. A representative consumer's preferences are defined over a vector of market goods, $\mathbf{X}$, a public good, $q$, but now we add leisure, $L$. Though we use a representative agent in developing our analytical points, it is not critical that everyone have identical preferences. We focus on a representative consumer because our observations need only be discussed in the context of a single individual; the main points carry directly over to multiple consumers with a wide variety of preferences for public and other goods. While our model is similar in spirit to the typical public goods analysis, the addition of leisure differs from the standard analysis. It is assumed that all goods are normal goods. The primal problem is to maximize utility by choosing levels of market goods $\mathbf{X}$ and leisure $L$ in a single period subject to the budget constraint $p \cdot \mathbf{X}$ $+\tau \cdot q+w \cdot L=w \cdot H$, and a rationed level of the public good $q=q^{0} . H$ is total time available and $\tau$ is the individual tax rate for providing the public good. The formal problem is stated as follows,

$\operatorname{Max} U(\mathbf{X}, q, L)$ in $\mathbf{X}, L$ subject to

$$
p \cdot \mathbf{X}+\tau \cdot q+w \cdot L=w \cdot H, q=q^{0} .
$$

The ordinary demands for market goods will depend on prices, the wage rate, the tax rate for the public good, and the level of the public good, $X^{m}=X^{m}(p, w, \tau, q)$, $L^{m}(p, w, \tau, q){ }^{4}$ While these ordinary demands dictate the observable behavior, they do not provide the proper insights into the monetary measures used in welfare analysis. In order to develop proper welfare measures, we consider the dual problem of minimizing expenditures on market goods and leisure subject to the level of $q$ and the level of utility,

\footnotetext{
${ }^{4}$ The $m$ superscript refers to ordinary, Marshallian solutions.
} 
$\operatorname{Min} p \cdot \mathbf{X}+\tau \cdot q+w \cdot L$ in $\mathbf{X}, L$, subject to

$$
U(\mathbf{X}, q, L)=U^{0}, q=q^{0} .
$$

The solutions to the dual problem depend on prices, the wage rate, the tax rate on the public good, the level of the public good, and the level of utility, $X^{h}=X^{h}$ $(p, w, \tau, q, U), L^{h}=L^{h}(p, w, \tau, q, U) .^{5}$ Using the demands, we can easily represent the amount of wealth adjustment that would leave our consumer indifferent between obtaining an increase in the public good from an initial level $q^{0}$ to a new, higher level $q^{1}$. As in standard welfare analysis that treats income as exogenous, the wealth adjustment that makes the consumer indifferent is referred to as compensating surplus $^{6}$ and is equal to the difference in the minimized expenditures,

$$
\begin{aligned}
C S= & p \cdot\left[X^{h}\left(p, w, \tau, q^{0}, U^{0}\right)-X^{h}\left(p, w, \tau, q^{1}, U^{1}\right)\right] \\
& +w \cdot\left[L^{h}\left(p, w, \tau, q^{0}, U^{0}\right)-L^{h}\left(p, w, \tau, q^{1}, U^{0}\right)\right] \\
& +\tau\left[q^{0}-q^{1}\right] .
\end{aligned}
$$

In order to contrast [3] with a standard welfare analysis that treats leisure demand as fixed, we constrain the choice of our consumer while providing the same increase in the public good. The minimization problem will be identical to the problem in [2], with the exception that leisure is constrained to the status quo level of leisure, which we will refer to as $L^{0}$. Now the only choice variables in the expenditure minimization problem are the levels of the market goods, $\mathbf{X}$. Given the constraint we alter our notation to reflect this constraint, $X_{S}^{h}=X_{S}^{h}\left(p, w, L^{0}, \tau, q, U^{0}\right)$, letting the " $S$ " subscript refer to the "standard" notion of compensated demand where leisure is fixed. With our new notation, we can express the

\footnotetext{
${ }^{5}$ The $h$ superscript refers to the solution to the dual problem, the compensated or Hicksian demands.

${ }^{6}$ Hicks 1943, p. 37, develops four consumer's surpluses, price compensating variation, quantity compensating variation, price equivalent variation, and quantity equivalent variation. Following Freeman (1993), we use the term compensating surplus instead of quantity compensating variation.
}

standard notion of compensating surplus found in the welfare economics literature,

$$
\begin{aligned}
C S_{S}= & p \cdot\left[X_{S}^{h}\left(p, w, L^{0}, \tau, q^{0}, U^{0}\right)\right. \\
& \left.-X_{S}^{h}\left(p, w, L^{0}, \tau, q^{1}, U^{0}\right)\right] \\
& +w\left[L^{0}-L^{0}\right]+\tau\left[q^{0}-q^{1}\right] .
\end{aligned}
$$

As our intuition suggests, the relationship between the standard compensating surplus [4] and compensating surplus with flexible leisure demand [3] is easy to establish.

Proposition 1: For an increase in the public good from $q^{0}$ to a new higher level $q^{1}$, it will generally be true that $C S_{S} \leq C S$. Furthermore, $C S_{S}<C S$, except when the income effect of compensated leisure demanded exactly equals the substitution effect of compensated leisure demand from $a$ change in $q$.

Proof, Part 1: The first statement in Proposition 1 is very easy to establish. First note that by definition $p \cdot X^{h}\left(p, w, \tau, q^{0}, U^{0}\right)$ $+w \cdot L^{h}\left(p, w, \tau, q^{0}, U^{0}\right)+\tau q^{0}=p \cdot X_{S}^{h}(p, w$, $\left.L^{0}, \tau, q^{0}, U^{0}\right)+w L^{0}+\tau q^{0}$; that is initial expenditures are equal for both problems. Given the respective minimization problems that provide the demands in [3] and [4], we know that it must be the case that $p \cdot X^{h}\left(p, w, \tau, q^{1}, U^{0}\right)+w \cdot L^{h}\left(p, w, \tau, q^{1}, U^{0}\right)$ $+\tau q^{1} \leq p \cdot X_{S}^{h}\left(p, w, L^{0}, \tau, q^{1}, U^{0}\right)+w L^{0}+\tau q^{1}$. The facts that initial expenditures are equal and $-\left[p \cdot X_{S}^{h}\left(p, w, L^{0}, \tau, q^{1}, U^{0}\right)+w L^{0}+\tau q^{1}\right]$ $\leq-\left[p \cdot X^{h}\left(p, w, \tau, q^{1}, U^{0}\right)+w \cdot L^{h}(p, w, \tau\right.$, $\left.\left.q^{1}, U^{0}\right)+\tau q^{1}\right]$ leads to the consequent $C S_{S}$ $\leq C S$.

Proof, PART 2: Part 1 of the proof establishes the weak inequality. To prove the second statement, we need only establish the conditions under which $C S_{S}=C S$. $C S_{S}=C S$ when $L^{h}\left(p, w, \tau, q^{0}, U^{0}\right)=L^{h}(p$, $\left.w, \tau, q^{1}, U^{0}\right)$, that is, when compensated leisure demand does not respond to the change in $q$. Compensated leisure demand from minimization problem [4] will differ from ordinary leisure demand in problem [1], once $q$ is changed from the initial level. The two diverge, since as $q$ is increased, wealth must be decreased in the compensated case. There will be an income effect if 
leisure responds to changes in wealth, regardless of whether leisure is a normal good, that is, increases with wealth, or an inferior good in the same sense. In the case of wealth-sensitive leisure, demand of either form (normal or inferior), $L^{h}\left(p, w, \tau, q^{0}\right.$, $\left.U^{0}\right)=L^{h}\left(p, w, \tau, q^{1}, U^{0}\right)$ only when the substitution effect exactly cancels out the effect of the reduction in income for the compensated demands. ${ }^{7}$ In the case where leisure demand is independent of wealth, then $L^{h}(p$, $\left.w, \tau, q^{0}, U^{0}\right)=L^{h}\left(p, w, \tau, q^{1}, U^{0}\right)$ only when there is no substitution effect. Both of these cases are the razor's edge, particularly the case where leisure demand is sensitive to wealth effects.

Willingness to accept compensation for a reduction in the public good is a particular case of compensating surplus. The initial level of the public good is the higher level and the initial utility level is the higher utility. For the decrease, standard compensating surplus is still less than compensating surplus. However these surpluses are both negative and so for reductions, ignoring income adjustments results in inferring that more compensation is required than is actually necessary. The intuition is easy to grasp. If leisure is flexible, less compensation is required to keep utility at the higher level when the public good is reduced, than when leisure is fixed. The general results on compensating surplus make intuitive sense. When leisure is flexible, a person will obtain maximum value for increases in the public good, relative to leisure fixed, and be willing to pay more. For decreases in the public good, flexibility dampens the blow and so less compensation is required. In either case, treating income as fixed results in measurement errors. In the United States, the analysis of natural resource damages and federal environmental policy relies on a willingness-to-pay approach, even in cases in which willingness to accept is the more appropriate concept. The justification for

${ }^{7}$ This condition is similar to the weak complementarity condition (Mäler 1974) that requires no changes in compensated demands for a change in public goods after a certain price for the weakly complementary good is reached. this policy is that it results in a more conservative approach to benefits assessment. Thus according to our analysis, the bulk of environmental policy analysis will result in a tendency to generally underprovide these public goods.

Analyzing the impact of assuming a fixed leisure demand/labor supply creates greater difficulties for equivalent variation. In the case of equivalent variation, a fixed income approach assumes that earned income after the change in the public good equals earned income before the change. When this assumption is violated, a fixed income approach infers the wrong earned income after the change takes place and infers the wrong income necessary to maintain the post-change utility level. Under a fixedincome approach, equivalent variation is essentially the difference between two incorrect money measures.

Further implications for welfare analysis flow from the fact that our analysis directly extends to price changes. A fixed-income approach will understate the welfare benefits of lower prices and overstate the welfare losses of higher prices when using compensating variation as the welfare measure. Thus our results really apply to welfare economics in general. It may be the case that changes in public goods may be implemented through pollution taxes instead of lump sum taxes as suggested in our model. Given the immediate extension of our results to price changes, our model readily handles this general class of problems. Simply set the direct tax rate to zero and simultaneously implement price changes with changes in public goods and we arrive at the analysis of pollution taxes.

\section{POLICY RELEVANCE}

While not critical to our point, it is useful to consider the historical pattern of public good provision, for specificity air quality provision. There will be, on the basis of prior actions, some initial level of air quality, $Q_{0}$ in Figure $1 . M B_{T R U E}$ depicts the true marginal value of the public good, when labor is allowed to vary optimally 


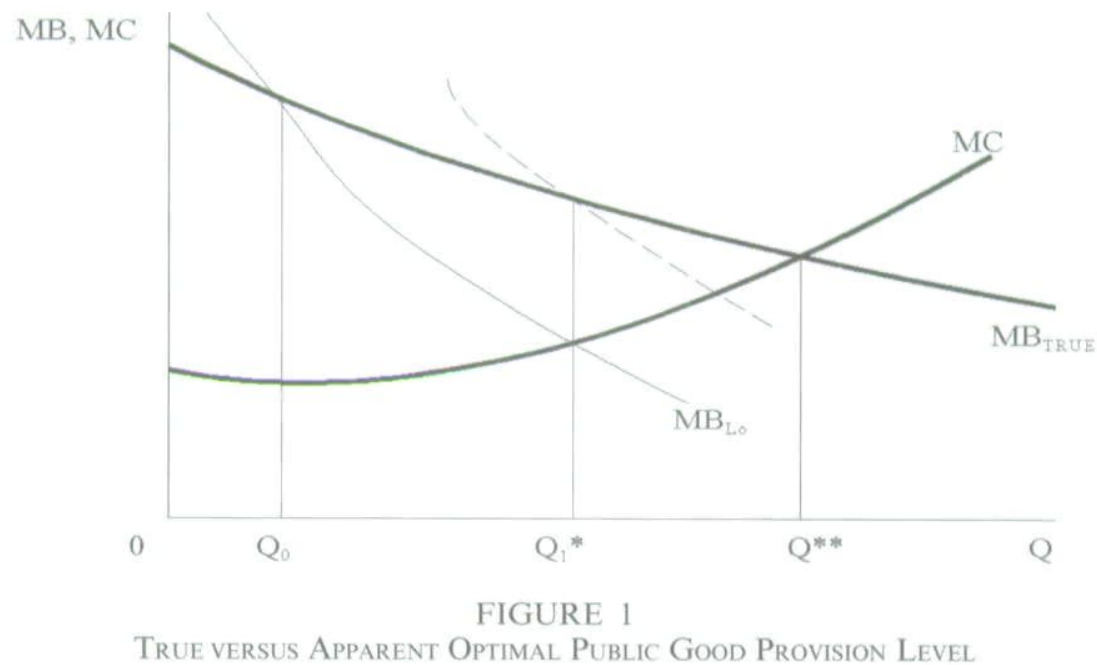

with public good provision, as discussed above. $M B_{L o}$ represents the marginal willingness-to-pay for the public good when the leisure is fixed at $L_{o}$, presuming for simplicity of argument that the well-known demand revelation problems have been solved. $L_{o}$ is also assumed, optimistically, to be the optimal level of leisure for the initial level of public goods provision, $Q_{0}{ }^{8}{ }^{8}$

$M C$ in Figure 1 represents the marginal provision cost of providing air quality, perhaps taking the form of higher prices for private goods in the case of air quality or higher tax payments for the case of municipal water treatment plants. Clearly, $Q^{* *}$ is the provision level of the public good that is socially optimal (the "optimum optimorum"), but that provision level would not be realized by a marginal analysis that relies on $M B_{L o}$. Rather, even in this idealized world of perfect demand revelation, $Q_{1}$ * would be selected by the regulatory authority, since they are evaluating the increment out of current income, not the income that would be generated at the higher public goods provision level.

It is true that, having provided $Q_{1}{ }^{*}$, there would be a new marginal willingness-to-pay curve associated with the reduced leisure

\footnotetext{
${ }^{8}$ Graves (2004) argues that the initial leisure chosen would be expected to be non-optimally large.
}

(hence greater income) that would ensue at the new provision level. This is shown as the dashed line in Figure 1. Were another benefit-cost analysis to be conducted, an increased level of provision would be seen as optimal. This process could, in principle, converge over time to the true optimum, $Q^{* *}$. However, benefit-cost analysis is costly and only sporadically conducted. Moreover, the true marginal willingnessto-pay curve is itself shifting outward over time with rising real incomes, ${ }^{9}$ making it difficult to discern whether the gap between actual provision and optimal provision is narrowing or widening despite increased provision levels.

In response to an anonymous reviewer's concern, we would like to address the interesting question of whether respondents actually endogenize potential labor supply responses in their stated-preferences. If they do, policy analysts will perceive accurate information from which to make environmental decisions. Moreover, it is clear that the hedonic method will not generally be

\footnotetext{
${ }^{9}$ Conventional empirical analyses of the relationship between willingness to pay and individuals' (fixed) incomes generally find a positive relationship, but the income elasticity of willingness to pay is frequently less than one (McFadden 1994). This positive relationship is all that is needed for the true marginal willingness-to-pay curve to shift out as real income rises.
} 
subject to the endogeneity problem emphasized here, because that approach to valuing environmental amenities essentially converts a spatially varying public good into a private good, bundled with land. We would be expected to properly generate income to buy the things that can be individually purchased via income generation.

But the concern of the reviewer is of considerable interest, prompting both theoretical and empirical exploration. One would expect that the "sum of specific damages" approach (sometimes called the "health effects" model) to valuing environmental damages would ignore the valuation problem emphasized here. ${ }^{10}$ This method is widely applied, and would result in undervaluation, implicitly holding leisure constant when optimal leisure would decline.

The case of constructed markets, employing contingent valuation or conjoint analysis, is not so straight-forward, since we do not know whether respondents think about possible changes in income when asked to value a good. To address this issue, one of the authors conducted a classroom survey to explore the possibility that respondents subconsciously endogenize, whether analysts consider that or not. To control for various forms of spurious correlation, two questionnaires were administered to university students, splitting the class, with half receiving one questionnaire and half the other. One of the questionnaires involved a "quasi-public" good (bike paths and hiking trails that could at least potentially be used by students) and one related to a pure public good (open space purchases for preservation and sprawl limitation).

In both cases, after asking for initial valuations - along with many traditional socio-demographic questions - a last question was added. That question was "most people decide on how much to contribute based on their current income, recognizing that the more they give to the fund the

\footnotetext{
${ }^{10}$ The values to be attached to the physical effects are determined from current incomes, not the incomes that would be generated in a general equilibrium context.
}

fewer other goods they can consume. However, the possibility of contributing to the fund might also cause people to want to change the number of hours they work, increasing their income. By increasing their income, any contribution could be made without giving up as many other goods. Thinking explicitly about this possibility, would you work more to increase your income?",11

For present purposes, a theoretical prediction is clear. The more "pure" the public good, the more likely it is that individuals would attempt to both "free ride" in the traditional sense, but also fail to think about endogenous changes in their work/ leisure decisions. The results of the survey suggest that the concerns of the present paper (and those of Graves 2004), might well be of empirical importance. When the "quasi-private" good was being considered, those surveyed expressed greater willingness to pay initially, as expected. But when the potential of working more hours to generate more income was raised, aggregate values rose by $33 \%$.

As expected from the analysis presented here (and from traditional free rider theory), the initial valuations were smallerabout $20 \%$ smaller in this specific casewhen the valuation elicited was for the pure public good. But, again as expected, when the potential for working more was raised, the additional expressed willingness to pay rose by $67 \%$, much larger than for the quasiprivate good. While we would not like to place undue emphasis on the quantitative results of these initial empirical inquiries, the qualitative results are consistent with the arguments presented here.

\section{CONCLUSIONS}

We argue that failure to endogenize the labor/leisure decision - conducting benefit-

${ }^{11}$ The full questionnaires and detailed results are available from the authors. Seven of 28 respondents elected to increase their contribution amounts for the pure public good while eight of 25 students increased their contributions for the quasi-public good. 
cost analysis at current income levelsgenerally results in undervaluation for increments to a public good. Intuitively, this follows from the fact that the cost of the public good increment will result in a higher marginal valuation of ordinary private goods as their quantities are reduced to pay for the public good, and this in turn will result in a higher marginal cost of leisure. We will work more at higher public good provision levels, hence will generate a higher income, and this effect is not considered, a priori. $^{12}$

One might initially suspect that endogenizing leisure would merely result in secondorder effects that would be negligible around the true optimum. This would be true if we were likely to be anywhere near the true optimum. $^{13}$ But with costly benefit-cost analyses conducted only infrequently, and with the true marginal benefits themselves shifting out over time with rising real income, we are unlikely to be near the true optimum. as depicted in Figure 1. The effects discussed here could result in substantial real-world under provision of public goods.

\footnotetext{
${ }^{12}$ This assertion relies on the assumption of independence among goods, leisure, and the public good. Strong complementarity between leisure and the public good weaken the argument for higher levels of generated income with higher levels of public goods. Strong complementarity would not be expected for pure public goods, but may occur for quasi-public goods such as recreation areas.

${ }^{13}$ Graves (2007) provides a plethora of arguments for downward-biased estimates of environmental benefits in benefit cost analysis as currently practiced.
}

\section{References}

Freeman, A. Myrick III. 1993. The Measurement of Environmental and Resource Values. Washington, D.C.: Resources for the Future.

Graves, Philip E. 2004. "On the Valuation of Pure Public Goods." Manuscript. Department of Economics, University of Colorado, Boulder.

- 2007. Environmental Economics: A Critique of Benefit-Cost Analysis. New York: Rowman and Littlefield.

Hicks, John R. 1943. "The Four Consumer's Surpluses." The Review of Economic Studies 11 (1): 31-41.

Just, Richard E., Darrell L. Hueth, and Andrew Schmidt. 1982. Applied Welfare Economics and Public Policy. Englewood Cliffs, N.J.: PrenticeHall.

McFadden, Daniel. 1994. "Contingent Valuation and Social Choice." American Journal of Agricultural Economics 76 (4): 689-708.

Mäler, Karl-Göran. 1974. Environmental Economics: A Theoretical Inquiry. Baltimore, Md.: Johns Hopkins University Press for Resources for the Future.

Samuelson, Paul A. 1954. "The Pure Theory of Public Expenditure." Review of Economics and Statistics 36 (4): 387-89. 
Copyright of Land Economics is the property of University of Wisconsin Press and its content may not be copied or emailed to multiple sites or posted to a listserv without the copyright holder's express written permission. However, users may print, download, or email articles for individual use. 